\title{
Quality of life evaluation after selected bariatric procedures using the Bariatric Analysis and Reporting Outcome System
}

\author{
Jacek Dadan, Paweł Iwacewicz, Hady Razak Hady \\ $1^{\text {st }}$ General and Endocrinology Surgery Department, Medical Univeristy, Bialystok, Poland
}

Videosurgery and other miniinvasive techniques 2010; 5 (3): 93-99 DOI: 10.5114/wiitm.2010.16419

\begin{abstract}
Introduction: Morbid obesity leads to significant decrease in quality of life. The Bariatric Analysis and Reporting Outcome System (BAROS) was created for objective evaluation of surgical treatment for morbid obesity outcomes. Aim: Evaluation of late results of surgical treatment for morbid obesity with laparoscopic adjustable gastric banding (LAGB) and Roux-en-Y gastric bypass (RYGB) procedures, together with evaluation of quality of life in the postoperative period.

Material and methods: Sixty patients treated surgically for morbid obesity were included in the study. Group 1 constituted patients who underwent $L A G B-n=30$ patients with mean age $34 \pm 9.67$, mean $B M I 44.3 \pm 3.7$. Group 2 constituted patients who underwent RYGB $-n=30$ patients with mean age $50.9 \pm 7.8$ years, mean BMI $54.5 \pm 6.72$. Patients were operated on in the period 2007-2008. At least 6 months after the operation, they received questionnaires based on the BAROS scale in the authors' own modification.

Results: In both groups of patients treated with $\angle A G B$ and RYGB, an excellent result of surgical treatment was achieved in $17 \%$ of patients, very good in $57 \%$, good in $23 \%$, fair in $1.5 \%$ and failure in $1.5 \%$. In the final evaluation of quality of life $(Q O L)$ in both groups treated with $L A G B$ and RYGB, QoL was significantly better in $55 \%$ of patients, better in $42 \%$, while in 3\% QoL was unchanged.

Conclusions: The quality of life of patients with morbid obesity, evaluated at least six months after the surgery, improves significantly following the bariatric operations performed most often so far, in both laparoscopic and classic technique.
\end{abstract}

Key words: quality of life, bariatric surgery, BAROS

\section{Introduction}

Obesity was recognized as a global problem by the World Health Organization (WHO) in 1997 [1] and defined as a disease in the course of which excessive fat accumulation reaches a level that can negatively influence the health. The body mass index, expressed as the quotient of body mass in kilograms and the height given in square metres, is used for clinical classification of magnitude of body mass.

In the last decade of the $20^{\text {th }}$ century, obesity reached epidemic levels, and in some regions of the globe it may even be called a pandemic [2-4]. The huge scale of the problem has particularly been apparent in the highly industrialised countries of Western Europe and Northern America. Obesity is associated with the development of diverse grave conditions such as: diabetes mellitus, arterial hypertension, coronary heart disease, heart failure, hyperlipidaemia, neoplasms, osteoarthritis, gastroesophageal reflux disease, respiratory insufficiency including sleep apnoea syndrome, and others [1].

Morbid obesity involves significant quality of life reduction, and obese patients are frequently exposed 
to social ostracism. Easy fatigability often causes inability to work, or even inability to perform basic home activities. Obesity frequently affects young people, causing serious limitations in both family and social functioning [5].

The Bariatric Analysis and Reporting Outcome System (BAROS) scale was created for objective evaluation of surgical treatment for morbid obesity and is one of the most popular methods in assessing the quality of life following bariatric surgery. This scale globally reflects the extent of the body mass reduction, resolution of co-morbidities, quality of life (specifically changes in self-esteem, physical activity, social involvement, ability to work and sexual activity), postoperative complications and presumptive reoperations. All parameters presented above are marked and depending on the attained sum the final score is given, ranging from a minimum result, classified as a failure, to the maximum - excellent. The BAROS scale allows objective comparison of the results of morbid obesity treatment with application of different surgical modalities [6, 7].

\section{Aim}

The aim of this study was to evaluate the longterm results of surgical treatment for morbid obesity in patients operated on in the $1^{\text {st }}$ General and Endocrinology Surgery Department of the Medical University of Bialystok (Poland) with laparoscopic adjustable gastric banding (LAGB) and Roux-en-Y gastric bypass (RYGB), together with quality of life assessment in the postoperative period using the BAROS scale.

\section{Material and methods}

Sixty patients treated surgically for morbid obesity in the 1st General and Endocrinology Surgery Department of the Medical University of Bialystok, Poland were eligible for this study. Qualification to the study group included patients fulfilling indications for bariatric surgery, that is $\mathrm{BMI} \geq 40$ or $\mathrm{BMI} \geq 35$ along with co-morbidities [8]. Patients with psychiatric disturbances and older than 65 years were disqualified from the surgical treatment of obesity. Depending on the surgical treatment applied, patients were divided into two groups. Patients with BMI up to $50 \mathrm{~kg} / \mathrm{m}^{2}$ were assigned to the group treated with $L A G B$, whereas subjects with $\mathrm{BMI}>50 \mathrm{~kg} / \mathrm{m}^{2}$ and patients encumbered with comorbidities usually were assigned to the RYGB group. Final choice of the operative method was also based on patients' preferences. Group 1 consisted of patients treated with LAGB $-n=30$ patients (24 females, 6 males) with mean age 34 \pm 9.67 , mean body weight $127.67 \pm 4.9 \mathrm{~kg}$, mean BMI $44.3 \pm 3.7$. Group 2 constituted patients treated with RYGB $-n=30$ patients (19 females, 11 males) with mean age $50.9 \pm 7.8$ years, mean body mass 147.1 $\pm 26.6 \mathrm{~kg}$ and mean BMI $54.5 \pm 6.72$. Patients were operated on in the period 2007-2008.

Roux-en-Y gastric bypass operation was performed in the open fashion in three major stages. First, a small stomach pouch was created, that was thereafter anastomosed with the bowel and finally jejuno-jejunostomy of the enzymatic loop and the digestive loop was performed. The length of the digestive loop was about $100 \mathrm{~cm}$. Gastro-jejunostomy was performed with the aid of a $25 \mathrm{~mm}$ circular stapler $[9,10]$.

Laparoscopic adjustable gastric banding operation required application of a silicon band containing an elastic balloon, that could be regulated by a port located subcutaneously, enabling injection and extraction of fluid. The band was applied around the upper part of the stomach and in this way two reservoirs were created - a smaller, superior one of $20 \mathrm{ml}$ volume and a significantly larger, inferior one $[9,10]$.

Patients, after at least 6 months from the LAGB or RYGB operation, received questionnaires based on the BAROS scale in the authors' own modification. The aim of the modification was simplification of the subjective assessment of the quality of life. It relied on the transformation of the points in the form of fractions from the original BAROS scale to the integral numbers in the survey. They were retransformed to decimal fractions in the final analysis. Questionnaires were sent by mail or distributed during the control visits. Parameters included in the BAROS scale and detailed grading scale are presented in Table I (Figure 1) [6]. Principles of the final assessment of the bariatric surgery based on the BAROS scale are shown in Table II (Figure 2) [6]. Table III illustrates the questionnaire filled in by patients. It contains subjective parameters, included in the BAROS scale, together with modified evaluation, elaborated in the clinic. The scale, modified 
Table I. Parameters included in BAROS scale

\begin{tabular}{|c|c|c|}
\hline \multirow[t]{5}{*}{ 1. Body mass reduction scoring } & \multicolumn{2}{|c|}{ Weight gain (-1 point) } \\
\hline & \multicolumn{2}{|c|}{ 0-24\% EWL (0 points) } \\
\hline & \multicolumn{2}{|c|}{ 25-49\% EWL (1 point) } \\
\hline & \multicolumn{2}{|c|}{ 50-74\% EWL (2 points) } \\
\hline & \multicolumn{2}{|c|}{ 75-100\% EWL (3 points) } \\
\hline \multirow[t]{5}{*}{ 2. Evaluation of health change } & \multicolumn{2}{|c|}{ Worsening of general health (-1 point) } \\
\hline & \multicolumn{2}{|c|}{ No influence on health (0 points) } \\
\hline & \multicolumn{2}{|c|}{ Some improvement of health (1 point) } \\
\hline & \multicolumn{2}{|c|}{ Resolution of one co-morbidity and improvement of other co-morbidities (2 points) } \\
\hline & \multicolumn{2}{|c|}{ Resolution of all disorders (3 points) } \\
\hline \multirow{6}{*}{\multicolumn{2}{|c|}{$\begin{array}{l}\text { 3. Subjective quality of life assessment } \\
\text { - } \text { change in self-esteem (-1 to } 1 \text { point) } \\
\text { - } \text { change in physical activity ( }-0.5 \text { to } 0.5 \text { points) } \\
\text { - change in social activity (- } 0.5 \text { to } 0.5 \text { points) } \\
\text { - change in ability to work ( }-0.5 \text { to } 0.5 \text { points) } \\
\text { - change in sexual activity (- } 0.5 \text { to } 0.5 \text { points) }\end{array}$}} & Final assessment of quality of life \\
\hline & & - significantly worse ( -3 to -2.25 points) \\
\hline & & - worse (-2 to -0.75 points) \\
\hline & & - no change (-0.5 to 0.5 points) \\
\hline & & - better (0.75 to 2 points) \\
\hline & & - significantly better (2.25 to 3 points) \\
\hline \multirow[t]{2}{*}{ 4. Complications and reoperations } & \multicolumn{2}{|c|}{ Presence of minor complications (-0.2 points), major (-1 point) } \\
\hline & \multicolumn{2}{|c|}{ Need for reoperation (-1 point) } \\
\hline
\end{tabular}

in that way, was straightforward and easier to fill in, more understandable and well appraised by patients. The obtained results of the individual components' values of the subjective quality of life assessment, in both study groups, were statistically analysed using the statistical software Statistica 8.0 PL (StatSoft Inc. USA). Arithmetic mean value and standard deviation were calculated.

\section{Results}

In both groups treated with LAGB and RYGB, an excellent outcome of the bariatric surgery was achieved in $17 \%$ of subjects, a very good result in $57 \%$, good in $23 \%$, fair in $1.5 \%$ and failure in $1.5 \%$. In the final quality of life assessment, both in the LAGB group and in the RYGB group, significantly better quality of life was found in $55 \%$ of patients, better in $42 \%$, though in $3 \%$ there was no change in the quality of life. Outcomes of the surgical treatment of morbid obesity using the modified BAROS scale in groups treated with LAGB and RYGB are shown in Table IV,
Table II. Principles of the final assessment based on BAROS scale

\begin{tabular}{|ll|}
\hline Score & Outcome of surgical treatment \\
\hline$<1$ point & Failure \\
\hline$>1$ point & Fair \\
\hline$>3$ points & Good \\
\hline$>5$ points & Very good \\
\hline$>7$ points & Excellent \\
\hline
\end{tabular}

and results of the final assessment of quality of life, at least 6 months following the surgery, in both groups are shown in Table $\mathrm{V}$.

\section{Conclusions}

The quality of life of patients with morbid obesity, evaluated at least six months after the surgery, improves significantly following the bariatric operations performed most often so far, by both laparoscopic and classic technique. 
Table III. Questionnaire filled in by patients (own modification)

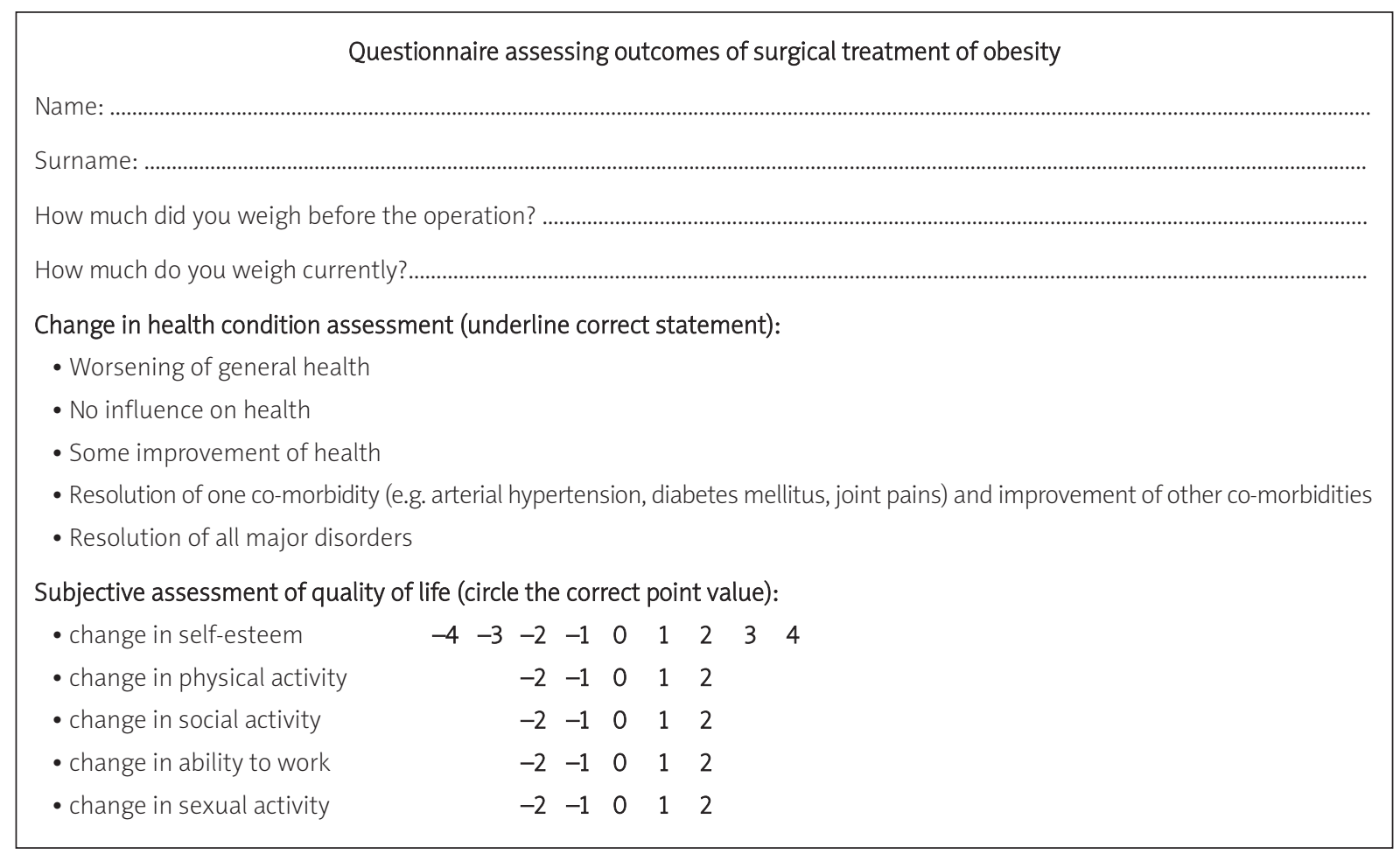

Table IV. Outcomes of obesity surgical treatment, based on BAROS scale in groups treated with LAGB and RYGB

\begin{tabular}{|lcc|}
\hline Final outcome & LAGB, $n(\%)$ & RYGB, $n(\%)$ \\
\hline Excellent & $7(23)$ & $3(10)$ \\
\hline Very good & $7(57)$ & $17(57)$ \\
\hline Good & $5(17)$ & $9(30)$ \\
\hline Fair & - & $1(3)$ \\
\hline Failure & $1(3)$ & - \\
\hline
\end{tabular}

Table V. Final evaluation of quality of life in groups treated with LAGB and RYGB based on BAROS scale

\begin{tabular}{|lcc|}
\hline Final quality of life outcome & LAGB, $n(\%)$ & RYGB, $n(\%)$ \\
\hline Significantly better & $24(80)$ & $9(30)$ \\
\hline Better & $5(17)$ & $20(67)$ \\
\hline No change & $1(3)$ & $1(3)$ \\
\hline Worse & - & - \\
\hline Significantly worse & - & - \\
\hline
\end{tabular}

\section{Discussion}

The overriding aim of bariatric surgery is improvement of health in the broad context, together with a beneficial impact on mental and socio-economic state, length of life and its quality as well. Hence, inclusion of co-morbidities observation and quality of life (QoL) assessment in the complex analysis of outcomes of surgical treatment for morbid obesity is very important. The BAROS scale, introduced by Oria and Moorhead, allows for an objective, patientfriendly, straightforward and comprehensive way of assessment of the results of bariatric treatment [11]. This scale covers three major areas: excess weight loss, improvement of co-morbidities course, and quality of life assessment. Points are deducted in the case of complications and reoperations. The BAROS scale has been used for over 10 years in many countries. Favretti et al. [12] in Italy used the scale to evaluate the results of treatment of 170 patients out of 350 who underwent LAGB, and in the USA Nguyen et al. [13] compared, also using the scale, the results of treatment of 155 patients with open and laparoscopic RYGB. In the case of the laparoscopic method $97 \%$ of patients, and $82 \%$ of subjects in the open group, 

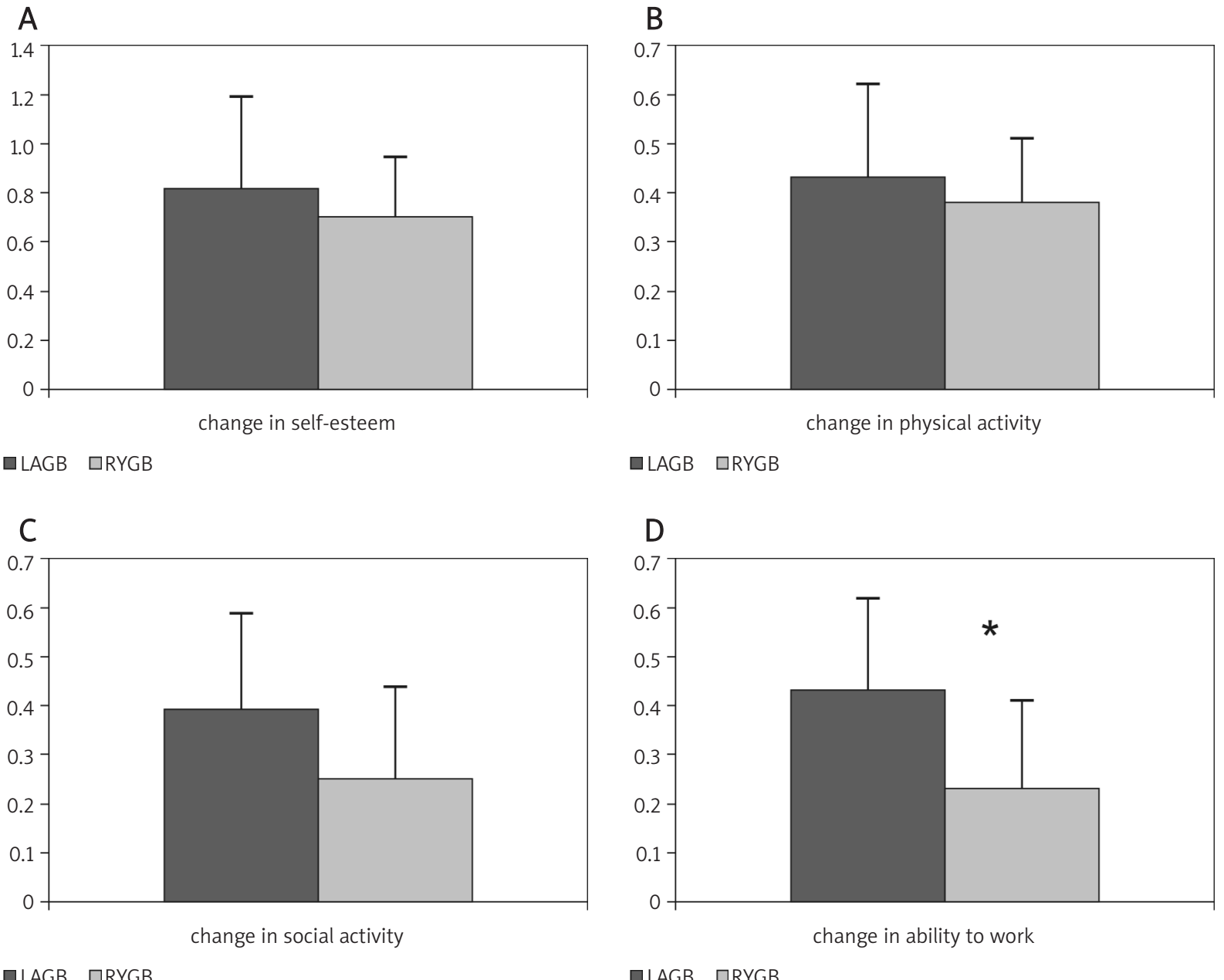

$\square$ LAGB $\square$ RYGB

$\square$ LAGB $\square R Y G B$

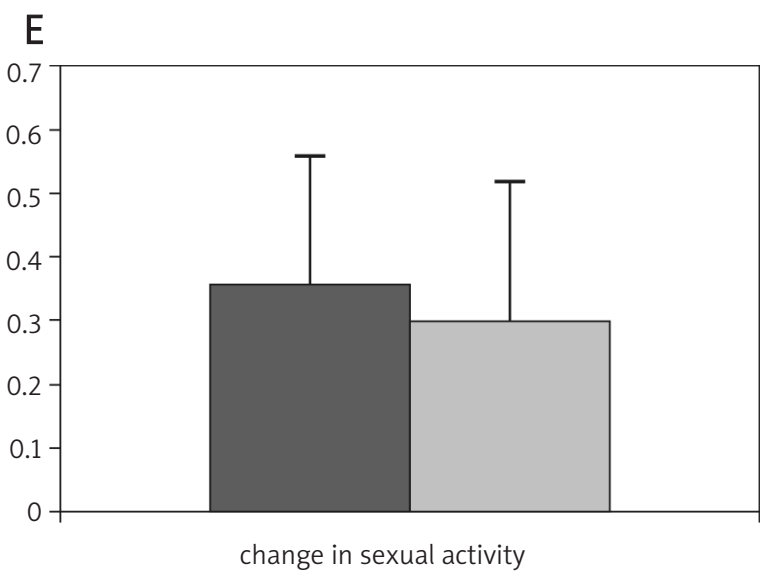

$\square$ LAGB $\square R Y G B$

had a good or very good final result, based on the BAROS scale. Myers et al. [14] evaluated the results of LAGB treatment of 57 subjects with a mean followup of 27 months. In $12 \%$ of subjects failure was

\begin{abstract}
Figure 1. Point values of particular components of the subjective quality of life assessment, in the LAGB group and the RYGB group, based on the BAROS scale. Maximum value possible to get in the case of self-esteem modification is 1 point, and 0.5 point for other components (mean values $\pm \mathrm{SD},{ }^{*} p<0.05$ )
\end{abstract}

reported, in $19 \%$ a fair result, in $36 \%$ good, in $19 \%$ very good, and in $13 \%$ an excellent result of treatment was observed. Multiple authors concluded that common use of the BAROS scale would allow for 


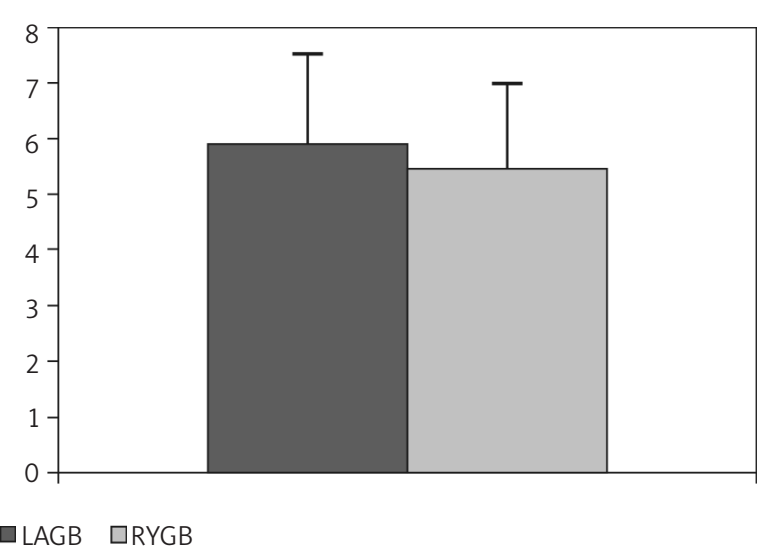

Figure 2. Comparison of the mean point values \pm SD of final score in groups treated with LAGB and RYGB using the BAROS scale

standardization in bariatric surgery [15]. This was also the reason for choosing this scale for the authors' own studies.

Experience with even a small group of patients operated for morbid obesity allows one to conclude that the quality of life following bariatric surgery improves significantly. Bariatric surgeons frequently encounter gratitude of patients, who often feel that after the surgery they have somehow returned to life. There are multiple questionnaires for quality of life analysis [16]. Usually they are very extended, sometimes they require an interlocutor, and they are rarely useful for longer observation [11]. For dozens of years, surgeons treated body mass loss as a major parameter in the assessment of surgical treatment of obesity, and criteria used in the assessment of treatment efficacy were frequently ambiguous and varied greatly depending on the authors. Pories et al. [16] assumed the loss of $\geq 25 \%$ of the initial body mass a success, whereas Freeman and Burchett [17] set the success level as a decrease by $15 \%$ of the preoperative mass. Halverson et al. [18] assumed a good treatment result as excess weight loss (EWL) $\geq 50 \%$, while according to Mason et al. [19] EWL of 25\% was sufficient.

Treatment choice in patients with morbid obesity depends on various factors, including patients' own preference. In the literature, there are no unequivocal criteria qualifying patients to the specific bariatric operation types, although most of the authors advise malabsorptive-restrictive procedures in patients with BMI above $50 \mathrm{~kg} / \mathrm{m}^{2}$, especially in the case of co-morbid conditions, e.g. diabetes mellitus type 2 and arterial hypertension.
Quality of life assessment in the postoperative period is a very important component of surgical treatment for obesity. Advances in bariatric surgery should be directed towards greater patient satisfaction and improvement in their quality of life. For objectification and extension of the evaluation of selected methods of surgical treatment for morbid obesity, in the endocrinology department, having 5 years' experience in bariatric surgery, it was decided to evaluate the quality of life of patients using the conventional BAROS scale. Based on this scale our own questionnaires were created, having modified scoring mainly with the aim of better comprehension and easier completion of questionnaires by patients. In the questionnaires all the fundamental areas of the BAROS scale were retained. The modification of the BAROS scale was performed because the original BAROS scale constitutes a certain standard for quality of life assessment, but, on its own, it does not meet the requirements of a questionnaire fully understandable for patients. The used questionnaires were positively received by patients, as was proved by its voluntary and keen completion by patients during the Out-patient Department visits or by mail. Patients did not have difficulties with understanding the questionnaires, which confirmed the benefits of introducing scoring modifications.

Assessing quality of life in the early postoperative period, certainly it would be better in the group treated by the laparoscopic method; hence in the background of the study was the assessment of the distant outcomes. In the conducted study almost all patients treated with LAGB got a very good or excellent final assessment result based on the BAROS scale, and only in one patient did failure occur, because of a lack of adherence to the dietary advice following gastric banding. In the patient group treated with RYGB also most of the patients confirmed very good or excellent results. In the quality of life questionnaire incorporated in the BAROS scale, almost all patients after LAGB gained a "significantly better" quality of life score, whereas after RYGB most of the patients obtained a "better" quality of life score. Comparing score values of the particular components of the subjective quality of life assessment in both groups, better results in the group treated with LAGB were noted. A statistically significantly greater change in the ability to work was shown to the advantage of the group following LAGB in comparison to the group after RYGB. Attained results, comparing quality of life 
in the long-term postoperative period, give evidence for the advantage of the laparoscopic methods over the classical operations and accentuate the value of minimally invasive techniques, although in both study groups quality of life improved significantly.

In recent years a change in the profile of bariatric operations is seen towards greater use of laparoscopic techniques, towards a decrease in the number of operations performed with the classical technique, and towards avoidance of irreversible extensive procedures changing anatomical relations. In the authors' department also this bariatric surgery evolution is clearly visible. In 2009 all RYGB operations were performed laparoscopically. This tendency has an undoubted influence on postoperative quality of life. Hence, it seems right to conduct further studies comparing only laparoscopic methods of LAGB and RYGB this time, also with use of the BAROS scale, in both the early and late postoperative period.

\section{References}

1. World Health Organization. Obesity. Preventing and Managing the Global Epidemic. WHO Technical Report Series No. 894. Geneva: WHO 2000.

2. Flegal KM, Caroll MD, Kuczmarski RJ. Overweight and obesity in the United States: prevalence and trends, 1960-1994. Int I Obes 1998; 22: 39-47.

3. Mogdad AH, Serdula MK, Dietz WH. The continuing epidemic of obesity in the United States. JAMA 2000; 284: 1650-1.

4. Mokdad AH, Serdula MK, Dietz WH. The spread of the obesity epidemic in the United States. JAMA 1999; 282: 1519-22.

5. Kolotkin RL, Head S, Hamilton M, Tse CK. Assessing impact of weight on quality of life. Obes Res 1995; 3: 49-56.

6. Wyleżoł M, Pardela M, Glück M, et al. Ocena wyników chirurgicznego leczenia skrajnej otyłości metodą laparoskopowego opasania żołądka opaską SAGB przy pomocy skali BAROS (Bariatric Analysis and Reporting Outcome System). Diabetologia Polska 2003; 10: 236-41.

7. Oria HE, Moorehead MK. Bariatric Analysis and Reporting Outcome System (BAROS). Obes Surg 1998; 4: 87-99.

8. Wyleżoł M, Paśnik K, Dąbrowiecki S, et al. Polskie rekomendacje w zakresie chirurgii bariatrycznej. Videosurgery and other miniinvasive techiques 2009; 4 (Suppl. 1): S31-4.

9. Stanowski E, Paśnik K. Chirurgiczne leczenie otyłości - aktualny stan wiedzy. Videosurgery and other miniinvasive techiques 2008; 3: 71-86.

10. Dadan J, Iwacewicz P, Hady RH. Nowe trendy w chirurgii bariatrycznej. Videosurgery and other miniinvasive techiques 2008; 3 : 66-70.

11. Oria HE, Moorehead MK. Updated Bariatric Analysis and Reporting Outcome System (BAROS). Surg Obes Relat Dis 2009; 5: 60-6.

12. Favretti F, Cadiere GB, Segato G. Bariatric Analysis and Reporting Outcome System (BAROS). Obes Surg 1998; 8: 500-4.
13. Nguyen NT, Goldman C, Rosenquist CT. Laparoscopic versus open gastric bypass: a randomized study of outcomes, quality of life, and costs. Ann Surg 2001; 11: 265-70.

14. Myers JA, Clifford JC, Sarker S, et al. Quality of life after laparoscopic adjustable banding using the BAROS and MooreheadArdelt Quality of Life Questionnaire II. JSLS 2006; 10: 414-20.

15. Sullivan MBE, Sullivan LGM, Kral KG. Quality of life assessment in obesity: physical, psychological, and social function. Gastroenterol Clin North Am 1987; 16: 33-42.

16. Pories WJ, Flickinger EC, Meelheim D. The effectiveness of gastric bypass over gastric partition in morbid obesity. Ann Surg 1982; 196: 389-99.

17. Freeman JB, Burchett $H$. Failure rate with gastric partitioning for morbid obesity. Am J Surg 1983; 145: 113-9.

18. Halverson JD, Zuckerman GR, Koehler RE. Gastric bypass for morbid obesity: a medical-surgical assessment. Ann Surg 1981; 194: 152-60.

19. Mason EE, Maher JW, Scott DH, et al. Ten years of vertical banded gastroplasty for severe obesity. Probl Gen Surg 1992; 9: 280-9. 